\title{
Practising physical therapy affects professionals in Egypt
}

\author{
DOI: https://doi.org/10.5114/pq.2020.96235
}

\author{
Mariam A. Ameer', Ahmed A. Ashour ${ }^{2}$ \\ ${ }^{1}$ Department of Biomechanics, Faculty of Physical Therapy, Cairo University, Giza, Egypt; Department of Physical \\ Therapy and Health Rehabilitation, College of Applied Medical Sciences, Jouf University, Al-Jouf, Saudi Arabia \\ ${ }^{2}$ Department of Biomechanics, Faculty of Physical Therapy, October 6 University, 6th of October City, Egypt
}

\section{Abstract}

Introduction. Physiotherapy is one of many professions at a high risk of work-related musculoskeletal disorders (WMSDs). The authors focused on job risk factors, frequency of occurrence, pain severity, and features of WMSDs among physical therapists in 11 governorates of Egypt.

Methods. A survey research interview including a standardized questionnaire was conducted with 220 physiotherapists from different clinics and hospitals in 11 governorates of Egypt.

Results. The most frequently involved body parts were the lower back (56.82\%), followed by the neck and upper back ( $14.55 \%$ and $11.82 \%$, respectively). Physiotherapists who worked at clinics were mostly affected. Physiotherapists working in the orthopaedic field were exposed to most work risk factors (63.18\%), followed by those in the paediatric and neurological fields $(25.91 \%$ and $10.91 \%$, respectively). Moreover, $66.82 \%$ of the physiotherapists were affected while using manual therapy methods in comparison with electro-manual and electrical methods. Female physiotherapists were more involved than their male counterparts $(62.73 \%$ and $37.27 \%$, respectively). There was a moderate positive correlation among the pain level of the affected body segment, the number of cases managed by the physiotherapist per day, and the number of work hours per day.

Conclusions. The results suggest that physiotherapists should follow a specific strategy to protect their bodies, especially the back areas. The use of engineering and administrative controls like a proper clinic design, application of electronic and computerized devices, and management of work time may help reduce the incidence of WMSDs.

Key words: physical therapy, work-related musculoskeletal disorders, risk factors, Egypt

\section{Introduction}

The existing evidence proves that physical therapists are at a high risk of work-related musculoskeletal disorders (WMSDs) and injuries [1-3]. They execute several physically demanding tasks that are related with WMSDs. These tasks are associated with frequent daily handling of patients, their repositioning and transfer. Awkward postures, recurrent trunk bending and twisting, lifting with quick maximal effort, pushing, pulling, repetitive motions and other human factors (cognitive, psychosocial, etc.) increase the risk of WMSDs among physical therapists $[4,5]$. WMSDs associated with a moderate to severe pain and most often affect different body parts [6]. They lead to work limitations, loss of work time, carrier shift, and heavy economic costs to healthcare systems and to companies.

Although evidence on WMSD risk in physical therapists exists, job risk factors, frequency of occurrence, pain severity, and features of WMSDs in this professional group are less well understood. These types of disorders are common among nurses and physical therapists with a moderately high risk $[7,8]$. It is essential to have the awareness of workplace settings to understand the causes and prevalence of WMSDs among physical therapists. Different workplace settings include public or private hospitals, private clinics, rehabilitation centres, home care, etc. Each of them requires different abilities and imposes many biomechanical demands on the musculoskeletal system [9-11]. It is also possible that the prevalence of WMSDs differs by specialties. However, there is little information about the rates of WMSDs among physical therapists practising in various specialties (e.g. orthopaedics, paediatrics, geriatrics, neurology, etc.). The most common specialty related to WMSDs is orthopaedics, with increased prevalence of symptoms within thumbs, wrist/hand, neck, upper back, low back, knee, and ankle/foot; 88.24\% (reflecting 15 subjects) of the recognized job-related risk factors were accompanied with either upper back or lower back symptoms [12]. Physical therapists can conduct their treatment with different methods, such as manual, electro-manual, and electrical ones. These methods differ in their effects on physical therapists; e.g., manual therapy is physically taxing and may affect thumb, wrist, or shoulder and cause pain in these areas [4]. Up to $70 \%$ of physical therapists suffer from WMSDs [13] and about half of them experience musculoskeletal pain in the initial 5 years of practice [14-16].

Establishing the distribution and prevalence of WMSDs among Egyptian physical therapists in various specialties and settings may help set the design an appropriate context of different rehabilitation and prevention programs. In addition, understanding the diverse risk and environmental factors, the anatomical sites of injuries, and the methods of treatment used by physical therapists is essential to guide education in this professional group $[4,17]$.

Few studies explored WMSDs among Egyptian physical therapists and none of them was conducted in different Egyptian governorates. Furthermore, the potential differences in the rates of WMSDs among specialties and settings need further evaluation. The same refers to the relationship between the pain level, the number of managed cases, and the level of experience. Therefore, the purpose of the study was to evalu-

Correspondence address: Mariam A. Ameer, Department of Biomechanics, Faculty of Physical Therapy, Cairo University, 7 Ahmed Elziat Street, Ben Elsarayat, El Dokki, 12612, Giza, Egypt, e-mail: mariam.abdelmonim@cu.edu.eg

Received: 24.01.2020

Accepted: 25.02 .2020

Citation: Ameer MA, Ashour AA. Practising physical therapy affects professionals in Egypt. Physiother Quart. 2020;28(4):42-47; doi: https:// doi.org/10.5114/pq.2020.96235. 
ate the characteristics and prevalence rate of WMSDs among physical therapists practising in 11 governorates of Egypt in accordance with their sex, setting, specialty, affected body parts, and methods of treatment used. In addition, the study aimed to find the relationship between the pain intensity, the number of treated patients, and the level of experience.

\section{Subjects and methods}

\section{Study population}

The study was based on 220 licensed physical therapists (82 males and 138 females). The participants were randomly selected from a list of licensed physical therapists living in 11 governorates of Egypt: Cairo (80 subjects), Giza (45 subjects), $6^{\text {th }}$ of October (5 subjects), Qalyubia (28 subjects), Faiyum (9 subjects), Sharqia (8 subjects), Suez (5 subjects), Ismailia (7 subjects), Dakahlia (10 subjects), Monufia (10 subjects), and Port Said (13 subjects). Owing to a table of random numbers, the 220 physical therapists were available for interview. The workplaces of all participants allowed considerable mobility and flexibility in alternating among different work tasks and most of the physical therapists adopted a standing or a seated posture. Some differences were found in the type of work conduction: manual, electro-manual, or electrical methods were applied. All selected physical therapists had a clinical experience of more than 1 year. Usually, the physical therapy sessions required from 45 minutes to 1 hour for each patient. The physical therapists took a regular rest break between sessions for about 10-15 minutes. Symptoms of discomfort or pain were scored for 8 body regions (neck, shoulder, elbow, wrist-hand, upper back, lower back, hip, and knee), in accordance with the body areas indicated in a previous paper [18]. Physical therapists who were retired or who had a professional experience shorter than 1 year were excluded.

\section{Interview questionnaire}

Demographic data were collected through a brief interview questionnaire. In-depth interviews concentrated on 3 categories of questions, related to (1) demographic data, (2) the work tasks, and (3) symptoms, as shown in Table 1. The factors related to demographic data gave factual information on the physical therapists' age, gender, body height, body weight, body mass index (BMI), and years of experience. Factors related to work tasks included geographical location, work setting, number of cases per day, number of hours at work, main specialty, and methods of treatment applied (manual, electro-manual, electrical only). Health-related factors represented mainly factors concerning symptoms, such as the most affected anatomical area or pain level as determined with the visual analogue scale (VAS).

The interviewers explained the content of the questionnaire to the respondents. All interviews were conducted by physical therapy consultants. Variables that were not factual information (qualitative data) were scored as numerical data to allow statistical procedures. Pain symptoms were detected by VAS; the reliability and validity of this scale was provided in several preceding studies [19-21]. All the physical therapists were appreciated for their response and participation.

\section{Statistical analysis}

The study data were analysed with the SPSS software, version 20.0. Data exploration was conducted to ensure the
Table 1. Interview questionnaire

\begin{tabular}{|l|}
\hline Demographic data \\
Age \\
Gender \\
Body height \\
Body weight \\
Body mass index \\
Years of experience \\
\hline Work-related factors \\
Governorate (geographical distribution) \\
Work setting \\
Number of cases per day \\
Number of hours at work \\
Specialty \\
Treatment methods used (manual, electro-manual, electrical) \\
Health-related factors \\
Most affected anatomical area \\
Pain level in the affected area (visual analogue scale)
\end{tabular}

homogeneity of data and exclude any outliers. Demographic results were determined with the use of MANOVA and expressed as mean ( \pm standard deviation). The variables of interests were presented as percentage and frequency. Crosstabulation was applied to detect the number of males and females in each variable of interests. Pearson product correlations served to detect the relationships between the pain intensity, level of work experience, number of cases per week, and number of hours at week.

\section{Ethical approval}

The research related to human use has complied with all the relevant national regulations and institutional policies, has followed the tenets of the Declaration of Helsinki, and has been approved by the ethical committee of the Faculty of Physical Therapy, Cairo University (P.T.REC/012/002165).

\section{Informed consent}

Informed consent has been obtained from all individuals included in this study.

\section{Results}

\section{Demographic characteristics}

Levene's test of equality of variances showed no statistically significant differences in the demographic data between male and female participants $(p>0.05)$. The results concerning the demographic data of all investigated physical therapists from 11 governorates of Egypt are demonstrated in Table 2. There were 138 female respondents (62.7\%) and 82 male participants (37.3\%). The mean age equalled 30.8 $( \pm 3.9)$ years among males and $30.9( \pm 4)$ years among females $(p>0.05)$. The respondents' body height was $167( \pm 3.1)$ $\mathrm{cm}$ in females and $170( \pm 2.6) \mathrm{cm}$ in males $(p<0.05)$. The average weight amounted to $68.6( \pm 5) \mathrm{kg}$ for females and $69( \pm 4) \mathrm{kg}$ for males $(p>0.05)$. Moreover, females had an average BMI of $24.5( \pm 1.4) \mathrm{kg} / \mathrm{m}^{2}$ and males had an average BMI of $23.8( \pm 1.3) \mathrm{kg} / \mathrm{m}^{2}(p<0.05)$. There was no significant difference in the professional experience between male (7.7 \pm 3.4 years) and female $(7.4 \pm 3.5$ years) physical therapists $(p>0.05)$. The range of the participants' clinical experience was $2-10$ years. 
Table 2. The physical therapists' demographic data, mean $( \pm S D)$

\begin{tabular}{|l|c|c|c|c|}
\cline { 2 - 5 } \multicolumn{1}{c|}{} & Age (years) & Height $(\mathrm{cm})$ & Weight $(\mathrm{kg})$ & BMI $\left(\mathrm{kg} / \mathrm{m}^{2}\right)$ \\
\hline Females & $30.9( \pm 4)$ & $167( \pm 3.1)$ & $68.6( \pm 5)$ & $24.5( \pm 1.4)$ \\
\hline Males & $30.8( \pm 3.9)$ & $170( \pm 2.6)$ & $69( \pm 4)$ & $23.8( \pm 1.3)$ \\
\hline$F$ & 0.026 & 46.83 & 0.385 & 13.26 \\
\hline$p$ & 0.871 & $0.000^{*}$ & 0.536 & 0.505 \\
\hline
\end{tabular}

$\mathrm{BMI}$ - body mass index

* Level of significance: $p<0.05$

Governorate

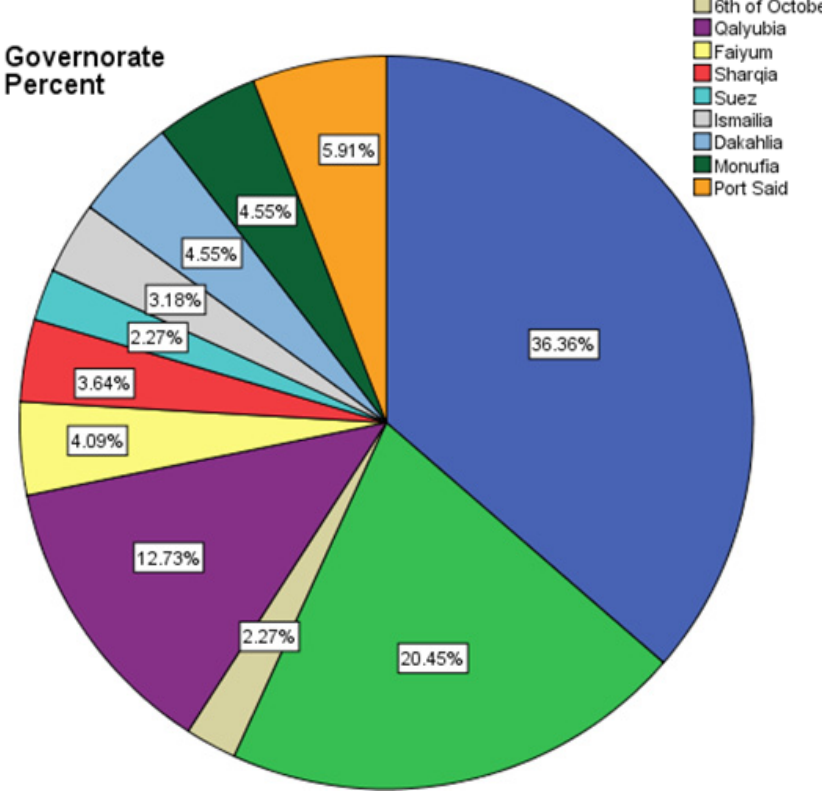

Figure 1. Geographical distribution of Egyptian physical therapists with WMSD

\section{Work-related factors (prevalence of WMSDs)}

Most Egyptian physical therapists who suffered from WMSDs were distributed in the 11 governorates of Egypt as shown in Figure 1. In relation to the work setting, the majority of the Egyptian physical therapists preferred working in clinics $(73.64 \%)$ to working in hospitals $(26.36 \%)$. The primary and most common specialties were orthopaedics (63.18\%), paediatrics (25.91\%), and neurology (10.91\%). The highest prevalence of WMSDs was found among physical therapists who used manual methods (66.8\%), followed by those who applied electro-manual (26.8\%) or electrical modalities only (6.4\%). Females (62.73\%) were more affected than males (37.27\%) (Table 3).

\section{Health-related factors}

The prevalence of WMSDs equalled $56.82 \%$ in the lower back, followed by $14.55 \%$ in the neck, $11.82 \%$ in the upper back, $7.7 \%$ in the shoulder, $3.2 \%$ in the wrist/hand, $2.7 \%$ in the knee, $1.8 \%$ in the elbow, and $1.4 \%$ in the hip (Table 3 ). Pearson product correlations revealed a moderate positive correlation between pain intensity as measured by VAS and the number of patient cases per day $(p<0.01)$. There was also a moderate positive correlation between the pain level and working hours per day $(p<0.01)$. Furthermore, there was a weak negative correlation between pain intensity and years of professional experience as a physical therapists $(p>0.01)$, as shown in Table 4.
Table 3. Work- and health-related factors

\begin{tabular}{|c|c|c|c|}
\hline & \multirow{3}{*}{$\begin{array}{c}\text { Males } \\
25(11 \%)\end{array}$} & \\
\hline & & & \multirow{2}{*}{$\begin{array}{l}\text { Females } \\
33(15 \%)\end{array}$} \\
\hline \multirow{2}{*}{ Work setting } & Hospital & & \\
\hline & Clinic & $57(26 \%)$ & 105 (48\%) \\
\hline \multirow{3}{*}{ Specialty } & Orthopaedics & $59(27 \%)$ & $80(36 \%)$ \\
\hline & Paediatrics & $12(5 \%)$ & $45(21 \%)$ \\
\hline & Neurology & $11(5 \%)$ & $13(6 \%)$ \\
\hline \multirow{3}{*}{$\begin{array}{l}\text { Treatment } \\
\text { methods }\end{array}$} & Manual & $55(25 \%)$ & $92(42 \%)$ \\
\hline & Electro-manual & $24(11 \%)$ & $35(16 \%)$ \\
\hline & Electrical & $3(1 \%)$ & $11(5 \%)$ \\
\hline \multirow{8}{*}{$\begin{array}{l}\text { Anatomical area } \\
\text { affected }\end{array}$} & Lower back & 52 (24\%) & $73(33 \%)$ \\
\hline & Neck & $12(5.5 \%)$ & 20 (9\%) \\
\hline & Upper back & $4(2 \%)$ & $22(10 \%)$ \\
\hline & Shoulder & $8(4 \%)$ & $9(4 \%)$ \\
\hline & Wrist/hand & $3(1 \%)$ & $4(2 \%)$ \\
\hline & Knee & $1(0.5 \%)$ & $5(2 \%)$ \\
\hline & Elbow & $0(0 \%)$ & $4(2 \%)$ \\
\hline & Hip & $2(1 \%)$ & $1(0.5 \%)$ \\
\hline
\end{tabular}

Table 4. Pearson product correlations of pain intensity and work-related factors

\begin{tabular}{|c|c|c|c|}
\cline { 2 - 4 } \multicolumn{1}{c|}{} & $\begin{array}{c}\text { Number } \\
\text { of cases } \\
\text { per day }\end{array}$ & $\begin{array}{c}\text { Working } \\
\text { hours } \\
\text { per day }\end{array}$ & $\begin{array}{c}\text { Years of } \\
\text { professional } \\
\text { experience }\end{array}$ \\
\hline Pain intensity (VAS) & $\begin{array}{c}r=0.587^{*} \\
p=0.00\end{array}$ & $\begin{array}{c}r=0.561^{*} \\
p=0.00\end{array}$ & $\begin{array}{c}r=-0.107 \\
p=0.112\end{array}$ \\
\hline
\end{tabular}

VAS - visual analogue scale

* Correlation significant at $p<0.01$

\section{Discussion}

The main goal of this interview survey was to obtain new information on the job risk factors, frequency of occurrence, pain severity, and features of WMSDs among physical therapists from 11 governorates of Egypt. The number of female participants $(62.7 \%)$ was approximately twice the number of male respondents (37.3\%). This may indicate that women were more willing to participate in such studies than men, as implied in a study by Bork et al. [22], in which female physical therapists were better represented than male physical therapists. The prevalence of WMSDs was higher among female physiotherapists, which is in agreement with the results of several previous studies [23-27]. It may seem that women are more physically active but weaker than men and this may put them at a risk during patient care, particularly when transferring and lifting heavy patients. In addition, physical therapists with increased BMI, especially over $25 \mathrm{~kg} / \mathrm{m}^{2}$, reported the highest prevalence of WMSDs (80\%) [28]. 
The obtained results concerning WMSDs in physiotherapists differed depending on the governorate; the prevalence of WMSDs was higher in Cairo (36.36\%), Giza (20.45\%), and Qalyubia (12.73\%) than in the other governorates of Egypt. These variations have to do with the number of a governorate population, the developmental level, and the status of the physical therapy profession in a given governorate [23]. The number of physiotherapists in urban areas is smaller than that in the rural regions if one considers the population size and density. According to the Central Agency for Public Mobilization and Statistics (CAPMAS), in 2017, rural areas in Egypt had higher employment rates than urban regions [29]. In addition, 1/3 of Cairo's population are village and small cities migrants [30]. The challenge of providing health services to the rural population is aggravated by health staff misdistribution and fewer facilities in rural areas and remote communities. Moreover, the number of patients in rural areas is higher than that in urban regions owing to low education and poverty. These factors put workforce stressors on physiotherapists in urban areas through increasing the number of cases, excessive activity, continuous workload, and patient complexity [31].

In relation to the work setting, the results of this study revealed that the number of physical therapists with WMSDs who worked in clinics was greater than of those in hospitals. This may imply that physical therapists prefer working in clinics to working in hospitals, possibly owing to more favourable financial conditions. Increased therapist-patient contact time in clinics may contribute to the higher incidence of WMSDs [28]. Moreover, the patients' health outcomes are better in the clinic than in the public hospital and the patients' anxiety is higher in hospitals than in private clinics [32]. Additionally, WMSDs were more prevalent among orthopaedic physical therapists, followed by those who practised in the field of paediatrics and neurology. In previous studies, $66.7 \%$ of orthopaedic physical therapists and all except 1 paediatric practitioners reported WMSDs during the previous 12 months $[22,28]$.

With reference to the treatment methods, the results showed a high incidence of WMSDs with using manual therapy techniques (massage, mobilizations, and manipulations; and improper lifting or transferring activities), followed by electro-manual methods. Manual therapy is considered as a main risk factor for WMSDs, and physical therapists who routinely applied manual therapy techniques were 3.5 times more expected to have musculoskeletal disorders than those who used other treatment methods [22]. The most common anatomical area affected by WMSDs in this study was the lower back region (24\%), followed by the neck (5.5\%) and the upper back $(2 \%)$. These results are in line with the outcomes of several previous studies [22, 25, 28, 33]. The reason for the high prevalence rate of lower back injuries among physical therapists is directly associated with patient care activities, such as transferring and lifting patients, lack of ergonomic controls at the workplace (frequent twisting and bending of the trunk), and prolonged standing [26, 34, 35].

The study indicated a moderate positive correlation between pain intensity and the number of cases per day and working hours per day ( $r=0.587$ and $r=0.561$, respectively), which corroborates a study by Ibrahim and Mohanadas [18]. Milhem et al. [36] found that increasing the number of patients per day might be considered as one of the most important risk factors for WMSDs and exacerbation of pain. Moreover, WMSDs are perceived as cumulative disorders that depend on the frequency and duration of exposure to risk factors [37].
Furthermore, the study indicated a weak negative correlation between pain intensity and years of professional experience. This finding was crucial in the context of conflicting ideas resulting from previous studies. Milhem et al. [36] reported that pain intensity and incidence of WMSDs were highest within the first 5 years of practice and among junior and newly graduated physical therapists. Cromie et al. [38] indicated that the highest prevalence of discomfort or pain in the lower back region was found in the youngest group. This may imply that older physical therapists have a limited patient contact time and they depend on the youngest physical therapists in their clinics [36]. On the other hand, Iqbal and Alghadir [39] observed that physical therapists with work experience longer than 5 years stated a higher prevalence of WMSDs than those with a shorter work experience, although the participants in this study were relatively young $(96 \%$ of them were under the age of 40 years), as the participants in our study, but the level of work experience in our study (may reach to 11 years of work experience) was higher than that in the quoted research $(62 \%$ of subjects had work experience shorter than 5 years). lqbal and Alghadir [39] pointed out that the causes of the high incidence of work-related pain among young physical therapists included overload in their work location, improper ergonomics, or wrong techniques used during patient care tasks. Also, newly qualified professionals do not appear to apply the principles of biomechanics or the instructions that they give to their patients for protection in their own practice.

\section{Limitations}

The limitations of the current study need to be recognized. We used an interview survey; qualitative methods frequently dictate small samples, and subjective interviews may skew the sample towards participants who find it easier to talk about their condition. Moreover, constraints were imposed on the time of interview to collect all the required data related to the Egyptian physical therapists in the rural and urban areas. Fortunately, the similarities between some of our essential question items and those found in previous studies allow confidence in the validity and analysis of the data.

\section{Conclusions}

This study concludes that the prevalence of work-related injuries among physiotherapists in Egypt is as high as that reported for other developed countries. The prevalence of WMSDs is higher in urban than in rural areas, and among females than among males. It turned out highest in therapists working in the orthopaedic, paediatric, and neurological specialties. Adequate preventive and management strategies are recommended to minimize work-related injuries in the physiotherapy practice. We need to emphasize the role of ergonomics and biomechanics in helping physiotherapists work competently and effectively.

\section{Acknowledgments}

The authors wish to thank all physiotherapists who participated in the present study. In addition, we gratefully acknowledge the Cairo University in Egypt for facilitating the sample selection.

\section{Disclosure statement}

No author has any financial interest or received any financial benefit from this research. 


\section{Conflict of interest}

The authors state no conflict of interest.

\section{References}

1. Glover W, McGregor A, Sullivan C, Hague J. Work-related musculoskeletal disorders affecting members of the Chartered Society of Physiotherapy. Physiotherapy. 2005;91(3):138-147; doi: 10.1016/j.physio.2005.06.001.

2. Waldrop S. Work-related injuries: preventing the PT from becoming the patient. Mag Phys Ther. 2004;12(2):34-41.

3. Darragh AR, Huddleston W, King P. Work-related musculoskeletal injuries and disorders among occupational and physical therapists. Am J Occup Ther. 2009;63(3): 351-362; doi: 10.5014/ajot.63.3.351.

4. Vieira ER, Schneider P, Guidera C, Gadotti IC, Brunt D. Work-related musculoskeletal disorders among physical therapists: a systematic review. J Back Musculoskelet Rehabil. 2016;29(3):417-428; doi: 10.3233/BMR-150649.

5. Keawduangdee P, Puntumetakul R, Swangnetr M, Laohasiriwong W, Settheetham D, Yamauchi J, et al. Prevalence of low back pain and associated factors among farmers during the rice transplanting process. J Phys Ther Sci. 2015;27(7):2239-2245; doi: 10.1589/jpts.27.2239.

6. Ekpenyong CE, Inyang UC. Associations between worker characteristics, workplace factors, and work-related musculoskeletal disorders: a cross-sectional study of male construction workers in Nigeria. Int J Occup Saf Ergon. 2015;20(3):447-462; doi: 10.1080/10803548.2014.110 77057.

7. Nyland LJ, Grimmer KA. Is undergraduate physiotherapy study a risk factor for low back pain? A prevalence study of LBP in physiotherapy students. BMC Musculoskelet Dis. 2003;4:22; doi: 10.1186/1471-2474-4-22.

8. Al-Eisa E, Buragadda S, Shaheen AAM, Ibrahim A, Melam GR. Work related musculoskeletal disorders: causes, prevalence and response among Egyptian and Saudi physical therapists. Middle-East J Sci Res. 2012;12(4): 523-529; doi: 10.5829/idosi.mejsr.2012.12.4.6632 .

9. Campo M, Weiser S, Koenig LK, Nordin M. Work-related musculoskeletal disorders in physical therapists: a prospective cohort study with 1-year follow-up. Phys Ther. 2008;88(5):608-619; doi: 10.2522/ptj.20070127.

10. Vieira ER, Svoboda S, Belniak A, Brunt D, Prix CRS, Roberts $\mathrm{L}$, et al. Work-related musculoskeletal disorders among physical therapists: an online survey. Disabil Rehabil. 2015;38(6):1-6; doi: 10.3109/09638288.2015. 1049375.

11. Tinubu BM, Mbada CE, Oyeyemi AL, Fabunmi AA. Workrelated musculoskeletal disorders among nurses in lbadan, South-west Nigeria: a cross-sectional survey. BMC Musculoskelet Disord. 2010;11:12; doi: 10.1186/14712474-11-12.

12. Lagman RAZ, Lipardo DS, Basilia CGL, Larracas JMU, Liabres GVT, Musni MMQ. Work-related musculoskeletal disorders of physical therapists in UST-CRS affiliated centers. Philip J Allied Health Sci. 2008;2(2):3-17; doi: 10.36413/pjahs.0202.001.

13. Salik Y, Ozcan A. Work-related musculoskeletal disorders: a survey of physical therapists in Izmir-Turkey. BMC Musculoskelet Disord. 2004;5:27; doi: 10.1186/14712474-5-27.

14. Rozenfeld V, Ribak J, Danziger J, Tsamir J, Carmeli E. Prevalence, risk factors and strategies in work-related musculoskeletal disorders among Israeli physical therapists. Physiother Res Int. 2010;15(3):176-184; doi:
15. Yasobant S, Rajkumar P. Work-related musculoskeletal disorders among health care professionals: a cross-sectional assessment of risk factors in a tertiary hospital, India. Indian J Occup Environ Med. 2014;18(2):75-81; doi: 10.4103/0019-5278.146896.

16. Anyfantis ID, Biska A. Musculoskeletal disorders among Greek physiotherapists: traditional and emerging risk factors. Safety Health Work. 2018;9(3):314-318; doi: 10.1016/j.shaw.2017.09.003.

17. Vieira ER. Work physical therapy and rehabilitation ergonomics: a review and discussion of the scope of the areas. Disabil Rehabil. 2006;28(24):1563-1566; doi: $10.1080 / 09638280600638182$.

18. Ibrahim NI, Mohanadas D. Prevalence of musculoskeletal disorders among staffs in specialized healthcare centre. Work. 2012;41(Suppl. 1):2452-2460; doi: 10.3233/ WOR-2012-0480-2452.

19. Boonstra AM, Schiphorst Preuper HR, Reneman MF, Posthumus JB, Stewart RE. Reliability and validity of the visual analogue scale for disability in patients with chronic musculoskeletal pain. Int J Rehabil Res. 2008;31(2): 165-169; doi: 10.1097/MRR.0b013e3282fc0f93.

20. Bijur PE, Silver W, Gallagher EJ. Reliability of the visual analog scale for measurement of acute pain. Acad Emerg Med.2001;8(12):1153-1157; doi: 10.1111/j.1553-2712. 2001.tb01132.x.

21. Myles PS, Myles DB, Galagher W, Boyd D, Chew C, MacDonald N, et al. Measuring acute postoperative pain using the visual analog scale: the minimal clinically important difference and patient acceptable symptom state. Br J Anaesth. 2017;118(3):424-429; doi: 10.1093/bja/ aew466.

22. Bork BE, Cook TM, Rosecrance JC, Engelhardt KA, Thomason ME, Wauford IJ, et al. Work-related musculoskeletal disorders among physical therapists. Phys Ther. 1996;76(8):827-835; doi: 10.1093/ptj/76.8.827.

23. Khairy WA, Bekhet AH, Sayed B, Elmetwally SE, Esayed AM, Jahan AM. Prevalence, profile, and response to work-related musculoskeletal disorders among Egyptian physiotherapists. Open Access Maced J Med Sci. 2019;7(10):1692-1699; doi: 10.3889/oamjms.2019.335.

24. King P, Huddleston W, Darragh AR. Work-related musculoskeletal disorders and injuries: differences among older and younger occupational and physical therapists. J Occup Rehabil. 2009;19(3):274-283; doi: 10. 1007/ s10926-009-9184-1.

25. Adegoke BOA, Akodu AK, Oyeyemi AL. Work-related musculoskeletal disorders among Nigerian physiotherapists. BMC Musculoskelet Disord. 2008;9:112; doi: 10.1186/1471-2474-9-112.

26. Mierzejewski M, Kumar S. Prevalence of low back pain among physical therapists in Edmonton, Canada. Disabil Rehabil.1997;19(8):309-317;doi:10.3109/0963828970 9166544.

27. Holder NL, Clark HA, DiBlasio JM, Hughes CL, Scherpf JW, Harding L, et al. Cause, prevalence, and response to occupational musculoskeletal injuries reported by physical therapists and physical therapist assistants. Phys Ther. 1999;79(7):642-652; doi: 10.1093/ptj/79.7.642.

28. Nordin NAM, Leonard JH, Thye NC. Work-related injuries among physiotherapists in public hospitals: a Southeast Asian picture. Clinics. 2011;66(3):373-378; doi: 10.1590/ s1807-59322011000300002.

29. Rural areas have higher employment rates than urban: CAPMAS. Egypt Today. May 1, 2018. Available from: http://www.egypttoday.com/Article/1/49086/Rural-areashave-higher-employment-rates-than-urban-CAPMAS. 
30. Abu-Lughod J. Migrant adjustment to city life: the Egyptian case. Am J Sociol. 1961;67(1):22-32; doi: 10.1177/ 019791836400100104.

31. Sheppard L. Work practices of rural and remote physiotherapists. Aust J Rural Health. 2001;9(2):84-90; doi: 10.1046/j.1440-1584.2001.00340.x.

32. Worsfold C, Langridge J, Spalding A, Mullee MA. Comparison between primary care physiotherapy education/ advice clinics and traditional hospital based physiotherapy treatment: a randomized trial. Br J Gen Pract. 1996; 46(404):165-168.

33. Glover W. Lifting the lid on work-related ill-health and musculoskeletal injury: CSP embarks on large-scale member study. Physiotherapy. 2003;89(7):394-395; doi: 10.1016/S0031-9406(05)60072-7.

34. Retsas A, Pinikahana J. Manual handling activities and injuries among nurses: an Australian hospital study. J Adv Nurs. 2000;31(4):875-883; doi: 10.1046/j.1365-2648.2000. 01362.x.

35. Souza d'Avila L, Fraga Sousa GA, Sampaio RF. Prevalence of work-related musculoskeletal disorders among physiotherapists in the public hospital system of Belo Horizonte [in Portuguese]. Rev Bras Fisioter. 2005;9(2): 219-225.

36. Milhem M, Kalichman L, Ezra D, Alperovitch-Najenson D. Work-related musculoskeletal disorders among physical therapists: a comprehensive narrative review. Int J Occup Med Environ Health. 2016;29(5):735-747; doi: 10.13075/ijomeh.1896.00620.

37. Barr AE, Barbe MF, Clark BD. Work-related musculoskeletal disorders of the hand and wrist: epidemiology, pathophysiology, and sensorimotor changes. J Orthop Sports Phys Ther. 2004;34(10):610-627; doi: 10.2519/ jospt.2004.34.10.610.

38. Cromie JE, Robertson VJ, Best MO. Work-related musculoskeletal disorders in physical therapists: prevalence, severity, risks, and responses. Phys Ther. 2000;80(4): 336-351; doi: 10.1093/ptj/80.4.336.

39. Iqbal Z, Alghadir A. Prevalence of work-related musculoskeletal disorders among physical therapists. Med Pr. 2015;66(4):459-469; doi: 10.13075/mp.5893.00142. 